\section{Dialogue, death, and life choices: a parent's perspective}

T his article is based on a talk I gave at the Institute of Child Health, London, in June 2005. When preparing it, I visited the auditorium and when I first entered, it reminded me physically-with speakers placed at the front and rows of chairs arranged "to sit and listen" in a hierarchy stretched upwards to the back-of the pattern of conversation our family frequently experienced within our medical system.

Through the uncertainty of Emelia's illness, life, and death, the structure of these conversations was often mutually frustrating and unhelpful. Their linear shape, defined by the expert and scientific search for answers and solutions and unable to provide either, led us down many a dead end. The conversations typically involved a lot of talking, the expression of set opinions and flexing of positions, and rarely valued our mutual ability to listen, in the moment, with the attention of both heart and mind. Reflecting on the verbal content and pattern of these conversations, I am reminded of the words of the Buddhist Thich Nhat Hanh: "he who speaks does not know, and he who knows does not speak".

I am reminded too of the mother of another little girl, a child who today is happy and healthy, and how this mother wept in a group meeting arranged by the hospital concerned, at the memory of how she had been ordered to leave her critically ill daughter, so the doctors could "better do their job"; at how she was talked at, not with; at how she felt her power and expertise as a parent and mother denied. It doesn't have to be like this.

We-Emilia's family and medical carers-managed to grope our way out of what seemed initially to be a kind of verbal darkness. We found through the relationships we built with and around her, opportunities to engage in dialogue that provided us with choices no matter that there were no life-saving solutions. For dialogue is not about providing answers so much as creating a meeting point where it becomes possible to embrace the mess and fallibility of simply being human, and still act with integrity and compassion. As our friend and one of Emelia's many consultants reflected recently: "it doesn't matter if what you say is not perfect, what's important is that it is from the heart".

When I look back at our many and varied experiences of the National Health Service during the 15 months of Emelia's life, the moments that stand

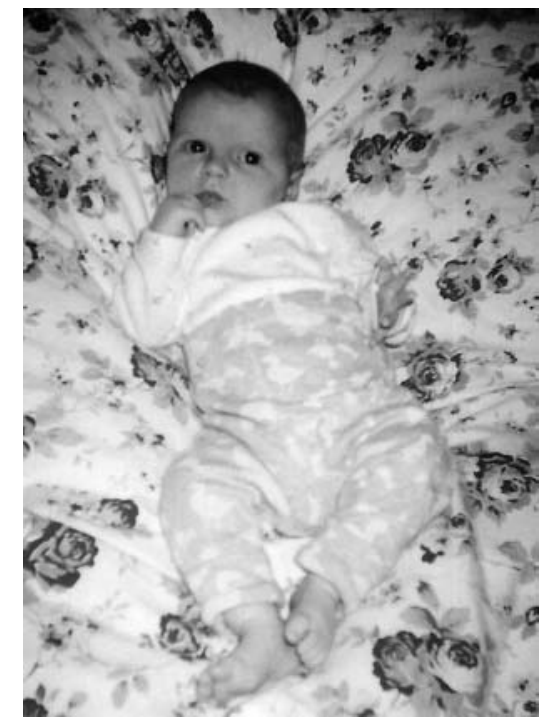

Consent was obtained for publication of this child.

out, the moments that made a positive difference to all our lives, seem to be less about the "what" and more about the "how". When I consider the "what", all in all the information we received about Emelia's illness was pretty consistent: a consensus about the all-elusive diagnosis and her clinical symptoms. But when I consider the "how" — how people cared for Emelia; and in particular how different people communicated and related with us as a family-there were significant differences. I believe these differences positively supported our care of Emelia so that we-and I include the medical professionals who came to know her-were able to support her in experiencing a good life and death.

And these positive "how" differences were simple human things-they were the consultant who was brave enough to consider Emelia a person and communicate with her, when so many others hid their uncertainty and fear behind charts, machines, and medical hypotheses; the nurse who encouraged us to play together after weeks of barrier and high tech paediatric intensive care, notably a nurse from the hospital's transitional care unit; and the consultant who in response to our request to take her home direct from the paediatric intensive care unit (PICU), said: "if that is what your intuition says then that is enough for me".

A defining feature of Emelia's life was the uncertainty about what might be causing her to be so ill. Not surprisingly, as a family we spent hours discussing various hypotheses, possible cures, and interventions with consultants from some 10 disciplines across three hospitals. Of all these often exhausting conversations, the most helpful one was where a consultant had the honesty to say they did not know. By then Emelia was acutely ill and had suffered two devastating episodes of status epilepticus. We were caught in a circular debate with various teams about further intervention and wanted to be sure that we were making choices that would support Emelia's own choice to live or die. And we wanted to avoid intervention that would provide little immediate relief. The consultant said simply that he could not predict Emelia's future and he could not say that she would not, or would, recover. However, he said that in the many years in his field he had not cared for a child with similar symptoms to Emelia's, and seen them make a complete recovery.

When I replay my memory of this conversation it seems that at the time we were less concerned with our own drive, and I include myself here, to provide heroic life-saving answers, wrapped up in endless espousing of expert opinion and counter opinion, and more attentive to what was actually being expressed in the room in that moment. Put simply, we were listening, together, in the living present. And within this dialogue a precious and choiceful truth opened for us: the possibility of Emelia living and dying well.

I imagine our relief soon after at discovering the field of palliative care is not common. We stumbled on the palliative care team while still on the PICU, and it seemed that each time we asked for treatment to be withheld there, we had the sense that the intensivists thought we were in some weird form of denial. Our conversations were apparently driven by fear, an unhelpful culture of heroic leadership, and very little listening at all. Looking back I see that I was as much a colluder in this pattern of conversation on the PICU as the staff.

When we asked doctors on the ward for the palliative team to be involved in Emelia's care it was as if we had pressed a magic verbal button and the system finally computed. Suddenly it became possible to go home, and to withdraw the invasive and painful medical treatments that had become standard fare. It seemed that until this moment we had been talking without ever 
acknowledging openly what we might call "the elephant in the room": that Emelia needed palliative support and that there were no known life-saving cures. By not naming the elephant, it had simply become bigger and bigger and our opinions all the louder to mask its presence. As the PICU consultants talked at us as if we expected a miracle cure, so we responded as if we they were completely incompetent. Each side became more and more entrenched and the conversation soon felt pretty choiceless. How different to the dialogue with the consultant who had said he did not know, where we let go of our fear for long enough to name "the elephant".

A month later Emelia returned to the PICU, this time in another hospital, with a secondary infection. I remember saying to the duty consultant at the time again that I wanted Emelia to have a natural life and for her to choose what she wanted to do with that life. And I said that at the same time I could not pretend I lived in a place where hightech equipment and medical support did not exist. So the question for us was how to find the balance, how to use the medical knowledge and technology to support her natural life. And given our exposure to high-tech medical management for what was several months by then, how to wean us-her family-off this, how to give us enough support as a family to feel confident about going home, with the strong likelihood we would not be coming back.

The consultant listened. And we listened as he spoke of the recent death of his own mother, and how difficult it had been for him to accept he could not save her. Again it seems looking back we were naming the elephant in the room.
We were focusing our attention on what we were thinking and feeling in the living present, rather than throwing past opinions and positions at each other across an imagined divide. And we brought to our dialogue not only our respective knowledge and expertise, but also our humanity-and the responsibility and risk that goes with this. Again we found choices where there were no apparent solutions. The outcome was that Emelia spent a summer at home enjoying the sunshine in her garden with the loving company of friends and family.

I imagine Emelia's life is in many ways unorthodox. For a child who was extremely ill for most of her life, she spent two thirds of it at home in a natural and familiar environment. While there were many moments of crisis in her life, three months after her last hospital discharge, she died peacefully with us, her family, at home, without distress or pain.

Since Emelia's death a number of medical professionals who were involved in her care have told us of how things are changing. Palliative care staff now attend the ward rounds on the PICU where we had so much unproductive communication. Our lead community nurse says that Emelia's story has radically changed her perspective about what is possible, and that she will never again simply assume that things cannot be done differently.

Emelia's life, and our experience within the NHS of caring for her, is an invitation for dialogue and new, shared learning. It is all too easy to forget that the scientific paradigm and medical machinery that supports it can often silence families and undermine their otherwise accepted role as primary carers for their children. At the same time, it can cast medical professionals (and parents) in unsustainable heroic roles, burdening them with the unrealistic expectation of controlling life and death outcomes; acknowledging death as an inevitable part of life transforms the structure of conversation, opening the possibility for choiceful dialogue about living and dying well between medical staff, families, and their children.

At the same time, the linear structure of solution orientated scientific inquiry, which often defines the culture of communication in hospitals, can be a cold companion for families and their children with incurable illness. It invites adversarial discussion and debate, and often creates a sense of bleak hopelessness, for all concerned. Dialoguewhere we listen and attend to our feelings and thinking in the moment, looking to create connection and emotional holding-offers the possibility of discovering unexpected affirming choices about how we live and die well.

And honouring our inevitable human fallibility, and what we do not know, can paradoxically be as reassuring and grounding as what we do know and can be certain of. For after all, death is the only certainty we all face. If we fear death we can "leak" this fear in our conversations and our relationships, creating imagined obstacles to choiceful dialogue. It is our responsibility as fellow human beings to attend to our relationship with the living and our mortality.

Julia Glyn-Pickeft

Mother to Emelia and Amy-Rose, and organisation consultant; julia.glyn-picket!@virgin.net 